\section{Cureus}

Received 05/31/2019

Review began 06/10/2019

Review ended 06/23/2019

Published 06/30/2019

\section{(C) Copyright 2019}

Young et al. This is an open access article distributed under the terms of the Creative Commons Attribution License CC-BY 3.0., which permits unrestricted use, distribution, and reproduction in any medium, provided the original author and source are credited.

\title{
Primary Epstein-Barr Virus Infection in an Adolescent Female Complicated by Acute Acalculous Cholecystitis
}

\author{
Callan Young ${ }^{1}$, Richard Lampe ${ }^{2}$
}

1. Pediatrics, Texas A\&M College of Medicine, Dallas, USA 2. Pediatrics, Texas Tech University Health Sciences Center, Lubbock, USA

$\square$ Corresponding author: Callan Young, cyoung1@medicine.tamhsc.edu Disclosures can be found in Additional Information at the end of the article

\section{Abstract}

Epstein-Barr Virus (EBV) is estimated to infect greater than 98\% of adults worldwide and is one of the most common human viruses. EBV infection can lead to acute infectious mononucleosis characterized by fever, fatigue, malaise, sore throat, and lymphadenopathy. Elevated liver function tests (LFTs) and hepatosplenomegaly may also be present. This infection usually lasts over a period of weeks or months and is self-limited. Infected individuals, however, may suffer rare complications. Acute acalculous cholecystitis (AAC) is an atypical complication of infectious mononucleosis. The case of a young healthy adolescent female with primary EBV infection complicated by AAC is reported. Providers should be aware that many pediatric and adult cases of AAC due to EBV resolve with conservative treatment. Surgical intervention has not been described as necessary or indicated in the context of AAC caused by EBV and should only be considered in severe cases that are not responding to conservative therapy.

Categories: Pediatrics, Pediatric Surgery, Infectious Disease

Keywords: pediatrics, epstein-barr, acute acalculous cholecystitis, adolescent, epstein-barr virus (ebv), conservative management, infectious mononucleosis

\section{Introduction}

Epstein-Barr Virus (EBV) is estimated to infect greater than 98\% of adults worldwide and is one of the most common human viruses [1]. Infection mainly occurs in early childhood and is predominantly asymptomatic. EBV infection can lead to acute infectious mononucleosis characterized by fever, fatigue, malaise, sore throat, and lymphadenopathy. Elevated liver function tests (LFTs) and hepatosplenomegaly may also be present. This infection usually lasts over a period of weeks or months and is self-limited. Infected individuals, however, may suffer rare respiratory, hematologic, hepatic, and/or psychological complications [1]. Acute acalculous cholecystitis (AAC) is an atypical complication of infectious mononucleosis. In this report, we present a case of primary EBV infection complicated by acute acalculous cholecystitis in an adolescent female.

\section{Case Presentation}

In August 2018, a previously healthy 14-year-old Caucasian female, body mass index (BMI) 22/Tanner Stage 5, presented to a regional hospital in Southern US with a three-day history of severe epigastric and right upper quadrant (RUQ) abdominal pain. She described the pain as sharp, almost constant, and worse with movement. She had been experiencing fatigue, nausea, vomiting, and anorexia for the past two to three weeks, which was treated with ondansetron. 


\section{Cureus}

Past medical history was significant for Attention Deficit Hyperactivity Disorder (ADHD), for which she recently started lisdexamfetamine (Vyvanse) one month prior. Physical exam was significant for RUQ and epigastric tenderness without rebound or guarding. The remaining physical exam findings were unremarkable; she did not present with fever, cervical lymphadenopathy, or hepatosplenomegaly. Vital signs were stable. Her temperature was $37.6^{\circ} \mathrm{C}$, heart rate was 70 beats per minute, respiratory rate was 20 breaths per minute, and blood pressure was 128/77 mmHg. Laboratory investigations revealed a white blood cell (WBC) count of $5.4 \mathrm{~K} / \mu \mathrm{L}$ (within normal ranges) with elevated lymphocytes (45.2\%) and monocytes (8.3\%). The remainder of her complete blood count (CBC) and complete metabolic panel (CMP) were within normal ranges - aspartate aminotransferase (AST) $22 \mathrm{U} / \mathrm{L}$, alanine aminotransferase (ALT) $13 \mathrm{U} / \mathrm{L}$, and total bilirubin $0.2 \mathrm{mg} / \mathrm{dL}$.

Based on her presentation, computed tomography (CT) abdomen/pelvis with contrast was performed, as appendicitis was originally suspected. The CT scan was positive for only gallbladder wall thickening. Ultrasound of the gallbladder (Figure 1) was then performed, revealing a thickened gallbladder wall of $1.0 \mathrm{~cm}(10 \mathrm{~mm})$ with associated pericholecystic fluid and elicitation of sonographic Murphy's sign. The absence of gallstones and biliary sludge was noted. Nuclear medicine hepatobiliary scan with cholecystokinin (CCK) was performed and showed prompt clearance of the radiotracer from the gallbladder to the small bowel, indicating the absence of biliary obstruction. The patient experienced mild RUQ pain and nausea after the administration of CCK. The gallbladder motility study was abnormal with a gallbladder ejection fraction (GBEF) of only $24 \%$. The normal GBEF fraction is greater than $35 \%$. Acalculous cholecystitis was then diagnosed and a surgical specialist was consulted. She was placed on empiric antibiotics (Piperacillin-Tazobactam $4.5 \mathrm{~g}$ intravenous (IV) every six hours) and an infectious disease specialist was consulted. Surgery was deferred pending investigation of etiology and further diagnostic workup was performed.

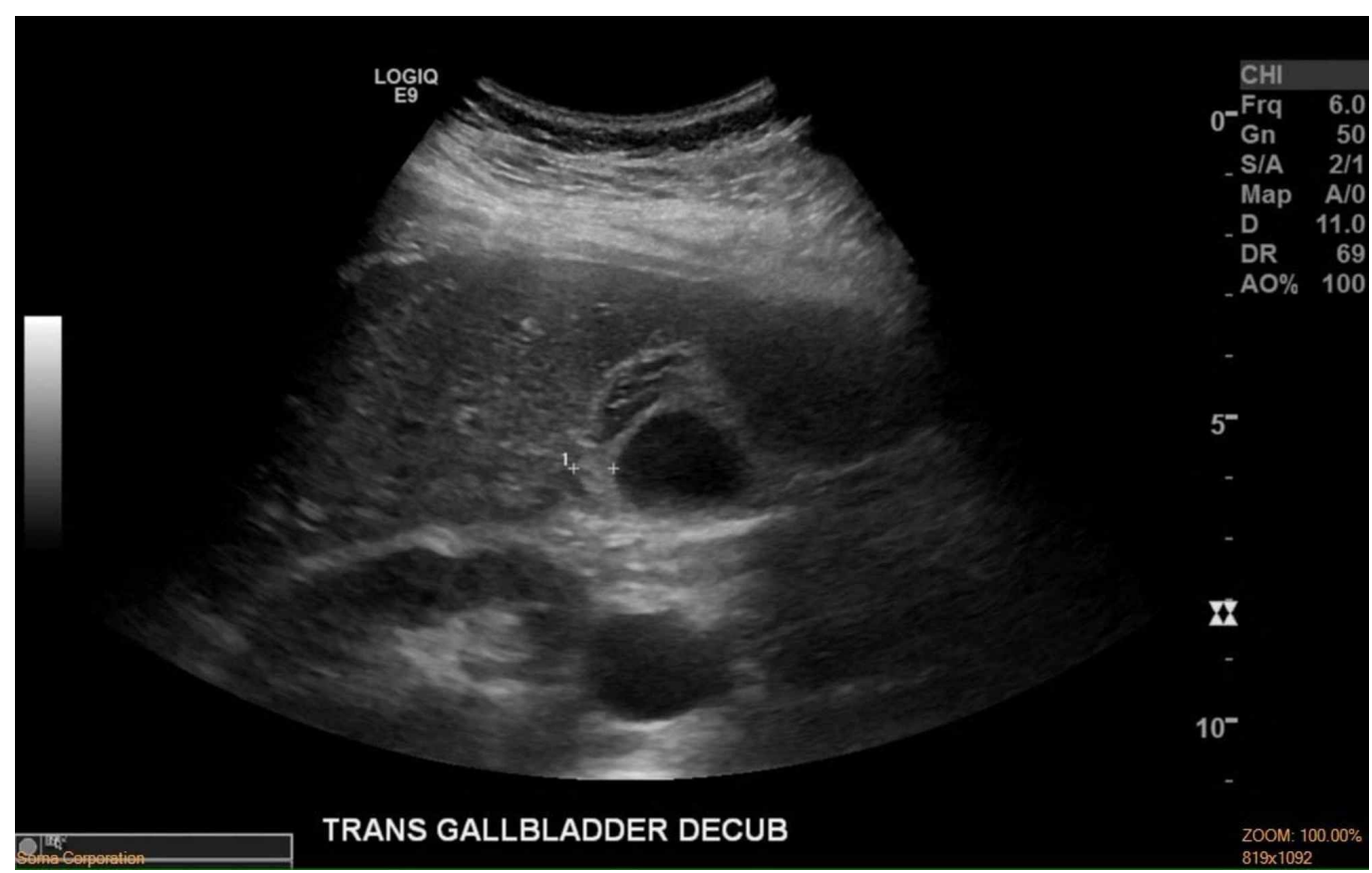

FIGURE 1: Gallbladder US showing $1.0 \mathrm{~cm}(10 \mathrm{~mm})$ gallbladder wall thickening without the presence of gallstones or sludge

$\mathrm{cm}=$ centimeters; US = ultrasound 
Viral etiology was suspected given the patient's report of recent fatigue and sick contact exposure. Adenovirus, human metapneumovirus, parainfluenza, rhinovirus deoxyribonucleic acid (DNA) panel polymerase chain reaction (PCR) was negative. Blood culture was negative. The hepatitis panel was negative and lipase levels were unremarkable. EBV viral serology panel resulted in positive EBV viral capsid antigen (VCA) immunoglobulin M (IgM) and nuclear antigen immunoglobulin $\mathrm{G}$ (IgG) titers, indicating acute EBV infection.

After an extensive multi-provider discussion, it was decided to treat the condition conservatively with ibuprofen and acetaminophen for pain and ondansetron for nausea as needed. Empiric antibiotics were discontinued after 48 hours following the positive EBV viral serology panel and negative blood culture. The patient's diet was advanced with full tolerance reached. Following significant improvement, the patient was discharged from the hospital two days later with close follow-up. Within two weeks following discharge, the patient was back to baseline activity with no residual abdominal pain or nausea. No follow-up imaging was performed due to full clinical improvement.

\section{Discussion}

Acute acalculous cholecystitis (AAC) is an inflammatory disease of the gallbladder with a multifactorial pathogenesis. AAC accounts for only $10 \%$ of all cases of acute cholecystitis in adults but $50 \%-70 \%$ of cases of acute cholecystitis in children [2]. Diagnosis is based on a variety of symptoms including fever, abdominal pain, leukocytosis, and/or elevated liver function tests. Radiologic features include gallbladder wall thickening greater than $3 \mathrm{~mm}$, gallbladder distention, pericholecystic fluid/sludge, and/or sonographic Murphy's sign [3]. Of the above criteria, a combination of two or more is diagnostic in the clinical setting. AAC caused by etiologies other than viral agents are most commonly treated with antibiotics and/or cholecystectomy.

Acute acalculous cholecystitis is commonly caused by viral infectious agents in children, and rarely in adults. Cases have been reported of Epstein-Barr Virus, cytomegalovirus, hepatitis A virus, Dengue virus and, more recently, Zika virus leading to AAC [4-5]. In 2015, a literature review conducted by Agergaard and Larsen [6] found that 27 cases had been reported on AAC secondary to EBV infection. Twenty-six of the patients were females and one was male. Twenty-two of the patients reported gastrointestinal symptoms. Thickened gallbladder wall was the most consistent finding in all cases, ranging from 4.2 to $15 \mathrm{~mm}$ thickness. In 2016, a literature review performed by Kottanattu et al. [7] identified 37 cases of AAC caused by EBV. Thirty-two of the patients were female and five of the patients were male. These cases recovered conservatively without surgery or corticosteroids [7]. Upon a literature review, at least 12 cases of AAC caused by EBV have been reported since the year 2016 [4,8-18]. Eight patients were females and four patients were males. Three patients were children and adolescents: a two-year-old male, a 14-year-old female, and a 16-year-old female [13-14,17]. The aforementioned articles may imply a female gender predilection of AAC caused by EBV. However, more extensive research is required to properly establish this predilection.

Most cases of AAC caused by EBV in adults, adolescents, and children resolve without the need for surgical intervention. In 2009, Chalupa et al. [19] discussed the case of a 22-year-old with AAC caused by EBV with suspected perforation of the gallbladder. Surgical intervention was not performed, even though perforation was suspected, and she recovered with conservative management. In 2018, Rezkallah et al. [8] presented the case of a 25-year-old woman with AAC caused by EBV that required a laparoscopic cholecystectomy due to intolerable abdominal pain. The patient recovered fully following surgical intervention. Antibiotics are not considered necessary in AAC caused by EBV, due to its viral etiology. However, antibiotics may be considered if gallbladder perforation is suspected and secondary bacterial complications are imminent [19]. Similarly, antiviral medications show no evidence of benefit and are not 
commonly utilized for uncomplicated cases [1]. In children and adolescents, the current mostcommon therapeutic management of AAC is conservative treatment. Hospital admission should be considered to monitor clinical improvement and prevent complications. Providers should be aware that many pediatric and adult cases of AAC due to EBV resolve with conservative treatment and without surgical intervention [2]. The literature surrounding the surgical treatment of AAC caused by EBV infection is sparse. However, in 2018, Graber et al. [9] discussed the case of a 14-year-old female who underwent laparoscopic cholecystectomy for AAC that was later confirmed to be caused by EBV. She died approximately two hours after surgery due to unexplained postoperative complications.

\section{Conclusions}

In conclusion, the case of a young healthy adolescent female with primary EBV infection complicated by AAC is reported. Our patient recovered fully with conservative treatment and without the need for surgical intervention. Surgical intervention has not been described as necessary or indicated in the context of AAC caused by EBV and should only be considered in severe cases that are not responding to conservative therapy.

\section{Appendices}

Key: $\mathrm{U} / \mathrm{L}=$ units/liter, $\mathrm{K} / \mu \mathrm{L}=1000 /$ microliter, $\mathrm{mg} / \mathrm{dL}=$ milligrams/deciliter

\section{Additional Information \\ Disclosures}

Human subjects: Consent was obtained by all participants in this study. Conflicts of interest: In compliance with the ICMJE uniform disclosure form, all authors declare the following:

Payment/services info: All authors have declared that no financial support was received from any organization for the submitted work. Financial relationships: All authors have declared that they have no financial relationships at present or within the previous three years with any organizations that might have an interest in the submitted work. Other relationships: All authors have declared that there are no other relationships or activities that could appear to have influenced the submitted work.

\section{References}

1. Jenson, H: Acute complications of Epstein-Barr virus infectious mononucleosis . Curr Opin Pediatr. 2000, 12:263-268. 10.1097/00008480-200006000-00016

2. Poddighe D, Sazonov V: Acute acalculous cholecystitis in children. World J Gastroenterol. 2018, 24:4870-4879. 10.3748/wjg.v24.i43.4870

3. Imamoğlu M, Sarihan H, Sari A, Ahmetoğlu A: Acute acalculous cholecystitis in children: diagnosis and treatment. J Pediatr Surg. 2002, 37:36-39. 10.1053/jpsu.2002.29423

4. Ono S, Kobayashi T, Nishio K: A case of acute acalculous cholecystitis during infectious mononucleosis caused by the Epstein-Barr virus in a young woman [Article in Japanese]. Kansenshogaku Zasshi. 2016, 90:330-335.

5. Gagneux-Brunon A, Suy F, Pouvaret A, et al.: Acute acalculous cholecystitis, a rare complication of Epstein-Barr virus primary infection: report of two cases and review. J Clin Virol. 2014, 61:173-175. 10.1016/j.jcv.2014.05.019

6. Agergaard J, Larsen C: Acute acalculous cholecystitis in a patient with primary Epstein-Barr virus infection: a case report and literature review. Int J Infect Dis. 2015, 35:67-72. 10.1016/j.ijid.2015.04.004

7. Kottanattu L, Lava S, Helbling R, Simonetti G, Bianchetti M, Milani G: Pancreatitis and cholecystitis in primary acute symptomatic Epstein-Barr virus infection - systematic review of the literature. J. Clin. Virol. 2016, 82:51-55. 10.1016/j.jcv.2016.06.017

8. Rezkallah K, Barakat K, Farrah A, Rao S, Sharma M, Chalise S, Zdunek T: Acute acalculous 
cholecystitis due to primary acute Epstein-Barr virus infection treated with laparoscopic cholecystectomy; a case report. Ann Med Surg (Lond). 2018, 35:189-191.

10.1016/j.amsu.2018.10.010

9. Graber M, Berg D, Jerde W, Kibort P, Olson A, Parkash V: Learning from tragedy: the Julia Berg story. Diagnosis (Berl). 2018, 5:257-266. 10.1515/dx-2018-0067

10. Hohn P, Braumann C, Uhl W, Luu A: Riddle me this: acalculous cholecystitis as an unusual complication of immunoglobulin M negative mononucleosis. Cureus. 2018, 10:e2505. Accessed: June 10, 2019: https://www.cureus.com/articles/10726-riddle-me-this-acalculouscholecystitis-as-an-unusual-complication-of-immunoglo....

11. Cameron A, Akilan K, Carr D: Infectious mononucleosis - not always a benign condition: a case report of infectious mononucleosis-associated acute acalculous cholecystitis. CJEM. 2019, 21:154-156. 10.1017/cem.2018.15

12. Yesilbag Z, Karadeniz A, Kaya F: Acute acalculous cholecystitis: a rare presentation of primary Epstein-Barr virus infection in adults-case report and review of the literature. Case Rep Infect Dis. 2017, 2017:5790102. 10.1155/2017/5790102

13. Say D, Chaparro J, Koning J, Sivagnanam M: Fever and jaundice in a previously healthy teenager. Clin Pediatr (Phila). 2016, 55:1081-1084. 10.1177/0009922816667311

14. Roda D, Huici M, Ricart S, Vila J, Fortuny C, Alsina L: Cholecystitis and nephrotic syndrome complicating Epstein-Barr virus primary infection. Paediatr Int Child Health. 2017, 37:74-77. 10.1080/20469047.2015.1135561

15. Khoury A, Porte F, Haq M: Epstein Barr virus, abdominal pain, and jaundice . BMJ. 2017, 358:j3386. 10.1136/bmj.j3386

16. Sheybani F, Naderi H, Erfani SS, Gharib M: A complicated course of acute viral induced pharyngitis, icteric hepatitis, acalculous cholecystitis, and skin rash. Case Rep Med. 2016, 2016:6796094. 10.1155/2016/6796094

17. Majdalani M, Milad N, Sahli Z, Rizk S: Acute acalculous cholecystitis in a Lebanese girl with primary Epstein-Barr viral infection. BMJ Case Rep. 2016, 2016: bcr2015213829. 10.1136/bcr2015-213829

18. Koufakis T, Gabranis I: Another report of acalculous cholecystitis in a Greek patient with infectious mononucleosis: a matter of luck or genetic predisposition?. Case Reports Hepatol. 2016, 2016:6080832. 10.1155/2016/6080832

19. Chalupa P, Kaspar M, Holub M: Acute acalculous cholecystitis with pericholecystitis in a patient with Epstein-Barr virus infectious mononucleosis. Med Sci Monit. 2009, 15:CS30-33. Accessed: June 10, 2019: https://www.medscimonit.com/download/index/idArt/869541. 